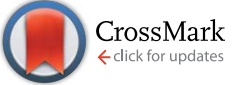

Cite this: RSC Adv., 2017, 7, 15842

\title{
Graphitic carbon nitride with $S$ and $O$ codoping for enhanced visible light photocatalytic performance
}

\begin{abstract}
Ran You, Hailong Dou, Lu Chen, Shaohui Zheng and Yongping Zhang*
Graphitic carbon nitride $\left(\mathrm{g}-\mathrm{C}_{3} \mathrm{~N}_{4}\right)$ shows great possibility to enhance its visible light photocatalytic performance by tuning its electronic structure and band gap via nonmetal element doping. $\mathrm{S}$ and $\mathrm{O}$ codoped $\mathrm{g}-\mathrm{C}_{3} \mathrm{~N}_{4}$ is synthesized by the polymerization of melamine and $\mathrm{H}_{2} \mathrm{O}_{2}$ bonded trithiocyanuric acid (TCA) at an elevated temperature and characterized as crimped nanosheets with mesoporous structures. The photocatalytic performance of $\mathrm{S}-\mathrm{O}$ codoped $\mathrm{g}-\mathrm{C}_{3} \mathrm{~N}_{4}$ for RhB degradation increases 6 fold by enhancing visible light adsorption and decreasing its band gap compared to pristine g- $\mathrm{C}_{3} \mathrm{~N}_{4}$ nanosheets. The substitution of the edge $\mathrm{N}$ with $\mathrm{S}$ and $\mathrm{O}$ dopant causes much more strongly delocalized HOMO and LUMO and increases the number of reactive sites, facilitating the migration of photogenerated electron/hole pairs.
\end{abstract}

Received 23rd January 2017 Accepted 3rd March 2017

DOI: 10.1039/c7ra01036b

rsc.li/rsc-advances methods, doping with nonmetal elements showed great possibility to enhance the visible light photocatalysis of $\mathrm{g}-\mathrm{C}_{3} \mathrm{~N}_{4}$, since the electronic structure and band gap changed dramatically via atomic doping. ${ }^{20}$ Carbon and nitrogen self-doped $\mathrm{g}-\mathrm{C}_{3} \mathrm{~N}_{4}$ exhibited improved photoreactivity by forming delocalized $\pi$ bonds to increase visible light absorption and electric conductivity. ${ }^{20,21}$ Many nonmetal heteroatoms, such as $\mathrm{B},{ }^{21-24}$ $\mathrm{P}^{25-28} \mathrm{~S},{ }^{29-36} \mathrm{O},{ }^{37-39}$ were introduced to improve the visible light photocatalytic activities for hydrogen generation and organic degradation compared with pristine $\mathrm{g}-\mathrm{C}_{3} \mathrm{~N}_{4}$. Experimental and theoretical studies showed that the dopants tune the electronic structure by forming localized states in the band gap, facilitating the transfer of photogenerated electron hole pairs. B-doped $g-\mathrm{C}_{3} \mathrm{~N}_{4}$ was usually prepared by heating melamine and boron oxide. ${ }^{23,24}$ Different molecular structures, however, were deduced, such as $\mathrm{C}^{-\mathrm{NB}_{2}}$ groups in the linkage ${ }^{23}$ and $\mathrm{B}$ atoms replacing $\mathrm{C}$ atoms in the $\mathrm{g}-\mathrm{C}_{3} \mathrm{~N}_{4}$ frame. ${ }^{24}$ As for S-doped $\mathrm{g}-\mathrm{C}_{3} \mathrm{~N}_{4}$, Hong et al. reported that the $\mathrm{S}$ atoms substitute the $\mathrm{C}$ sites, ${ }^{29}$ while some researchers reported that the doped S forms the $\mathrm{S}-\mathrm{C}$ bond in the triazine frame by replacing the $\mathrm{N}$ sites. ${ }^{33-35}$ Different preparation techniques may affect the substitution sites with dopant atoms, which leads to different electronic structures and subsequently affects the photocatalytic performance. Contradictions still exist about how to prepare, characterize and understand its mechanism. Therefore, further experimental and theoretical investigations are needed to gain deeper insight into the mechanism of photocatalytic performance via element doping. It is meaningful to explore a simple and effective approach to synthesize an efficient $\mathrm{g}-\mathrm{C}_{3} \mathrm{~N}_{4}$ photocatalyst via atomic doping with single or twofold elements and to study the dopant effect on the photocatalytic performance.

A valid pathway to improve the photocatalytic performance of $\mathrm{g}-\mathrm{C}_{3} \mathrm{~N}_{4}$ is by changing its electronic band structure and 
increasing the number of reactive sites via atomic doping. In this paper, we report a pathway to improve the photocatalytic performance by introducing $\mathrm{S}$ and $\mathrm{O}$ atoms into the $\mathrm{g}-\mathrm{C}_{3} \mathrm{~N}_{4}$ lattice. The experiments revealed that the $\mathrm{S}-\mathrm{O}$ codoped $\mathrm{g}-\mathrm{C}_{3} \mathrm{~N}_{4}$ exhibits superior photoreactivity for $\mathrm{RhB}$ degradation under visible light irradiation. Density functional theory calculations showed that the $\mathrm{S}$ doping decreases the band gap and increases the number of reactive sites, facilitating the transfer of photogenerated electron-hole pairs. This work provides a facile way to modulate the intrinsic electronic and band structure of $g-\mathrm{C}_{3} \mathrm{~N}_{4}$.

\section{Experimental details}

$0.01 \mathrm{~mol}$ of melamine (M) powder was dissolved into $30 \mathrm{~mL}$ of water solution with $30 \% \mathrm{H}_{2} \mathrm{O}_{2}$ in mass percentage. Then the solution was fully mixed inside a beaker and dried at $60{ }^{\circ} \mathrm{C}$ overnight. The obtained white substance was mixed with 0.01 mol of trithiocyanuric acid (TCA), and ground into a powder and then transferred to a silica boat with a cover and heated at $550{ }^{\circ} \mathrm{C}$ for $2 \mathrm{~h}$ in a nitrogen atmosphere. The obtained S-O doped $\mathrm{g}-\mathrm{C}_{3} \mathrm{~N}_{4}$ product was a yellow powder and was collected for further use. The $\mathrm{S}$ doped $\mathrm{g}-\mathrm{C}_{3} \mathrm{~N}_{4}$ was prepared in the same way without the $\mathrm{H}_{2} \mathrm{O}_{2}$ solution being involved in the preparation process. Scheme 1 illustrated the facile process for preparing the pristine $(\mathrm{CN})$ and the doped $\mathrm{g}-\mathrm{C}_{3} \mathrm{~N}_{4}$ with $\mathrm{S}(\mathrm{S}-\mathrm{CN})$ and $\mathrm{S}-\mathrm{O}(\mathrm{S}, \mathrm{O}-\mathrm{CN})$ elements.

The surface morphology was observed by a scanning electron microscope (SEM, JSE-7800F, Jeol). X-ray diffraction (XRD) measurements were used to characterize the crystalline structures of the $\mathrm{g}-\mathrm{C}_{3} \mathrm{~N}_{4}$ by a diffractometer (ShimadzuXRD7000) with $\mathrm{Cu} \mathrm{K} \alpha$ radiation $(\lambda=1.5418 \AA)$. The vibrational information was measured using a Fourier transform infrared (FTIR, PerkinElmer) spectroscopy instrument in $\mathrm{KBr}$ pellets. X-ray photoelectron spectroscopy (XPS) was carried out to analyze the chemical state and composition on a VG ESCALAB 250 spectrometer with $\mathrm{Al} \mathrm{K} \alpha$ radiation ( $h \nu=1486.8 \mathrm{eV}$ ). Ultravioletvisible (UV-vis) absorption spectra were performed on a U-3310 spectrophotometer (Hitachi, Japan) in the wavelength range of $300 \mathrm{~nm}$ to $800 \mathrm{~nm}$. Photoluminescence (PL) spectra were carried out on an F-7000 fluorescence spectrophotometer (Hitachi,

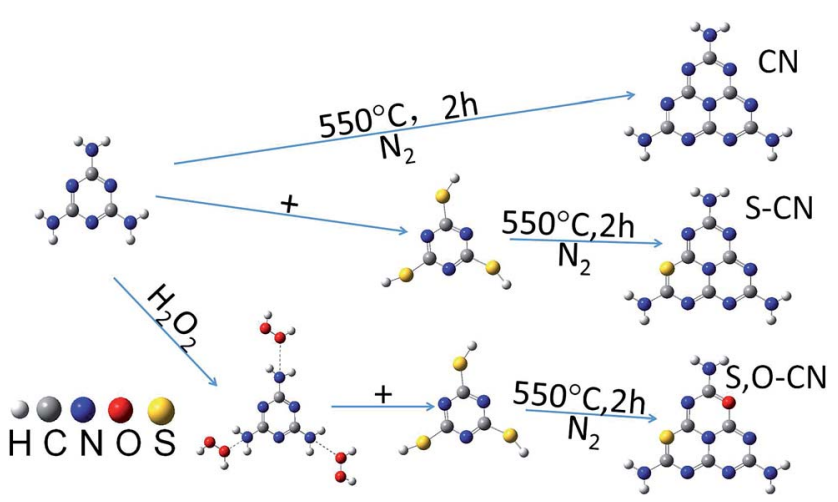

Scheme 1 Facial preparation process of the pure and S-O doped g$\mathrm{C}_{3} \mathrm{~N}_{4}$.
Japan) with an excitation wavelength at $273 \mathrm{~nm}$ using a $150 \mathrm{~W}$ Xe lamp as the excitation source.

The photocatalytic performance was evaluated by the degradation of Rhodamine $\mathrm{B}(\mathrm{RhB})$ in an aqueous solution under visible light irradiation using a $500 \mathrm{~W}$ Xe lamp as light source. $50 \mathrm{mg}$ of photocatalyst was dispersed in RhB aqueous solution (50 $\mathrm{mL}, 10 \mathrm{ppm})$. Prior to irradiation, the suspension was magnetically stirred in a dark room for $1 \mathrm{~h}$ to reach adsorptiondesorption equilibrium. During the irradiation process, $1 \mathrm{~mL}$ of the suspension was taken from the reaction cell at $30 \mathrm{~min}$ intervals for measuring the characteristic UV-vis absorption spectra after centrifugation. The maximum absorption peak was recorded and used to evaluate the concentration of RhB. The degradation rate of $\mathrm{RhB}$ can be calculated by definition:

$$
\text { Degradation rate }=\left(C_{0}-C\right) / C_{0}
$$

where $C_{0}$ is the adsorption-desorption equilibrium concentration of $\mathrm{RhB}$ and $\mathrm{C}$ is the concentration of $\mathrm{RhB}$ at reaction time $t$.

\section{Results and discussion}

The SEM image of the pristine $\mathrm{g}-\mathrm{C}_{3} \mathrm{~N}_{4}$ nanosheets, shown in Fig. 1(a), indicates the $\mathrm{g}-\mathrm{C}_{3} \mathrm{~N}_{4}$ nanosheets appearing as a lamella structure with some crinkles. The $\mathrm{S}$ doped $\mathrm{g}-\mathrm{C}_{3} \mathrm{~N}_{4}$ in Fig. 1(b) appears as an elongated slate and crimped $\mathrm{g}-\mathrm{C}_{3} \mathrm{~N}_{4}$ sheets with irregular mesoporous structures after the $\mathbf{M}$ had reacted with TCA at an elevated temperature. This may be ascribed to the polymerization reaction of $-\mathrm{SH}$ in TCA and $-\mathrm{NH}$ in $\mathrm{M}$ facilitating the formation of larger $\mathrm{g}-\mathrm{C}_{3} \mathrm{~N}_{4}$ sheets. After the $\mathrm{H}_{2} \mathrm{O}_{2}$ hydrothermal treatment, the $\mathrm{g}-\mathrm{C}_{3} \mathrm{~N}_{4}$ sheets in Fig. 1(c) become longer and the lamella structures even more curved than those of the $\mathrm{S}$ doped $\mathrm{g}-\mathrm{C}_{3} \mathrm{~N}_{4}$ with irregular porous structures. The mesoporous structures may result from the decomposition of TCA during the polymerization process. ${ }^{16}$ The energy dispersive $\mathrm{X}$-ray spectrum (EDS) analysis shows the composition of the $\mathrm{S}-\mathrm{O}$ doped $\mathrm{g}-\mathrm{C}_{3} \mathrm{~N}_{4}$, comprising rich carbon (C) and nitrogen $(\mathrm{N})$ with dispersed $\mathrm{S}$ and $\mathrm{O}$ elements. The overlapped C, N, S and O elemental EDS image (Fig. 1(d)) shows that the S and $\mathrm{O}$ elements are dispersed in $\mathrm{g}-\mathrm{C}_{3} \mathrm{~N}_{4}$ sheets. The EDS elemental mappings in Fig. $1(\mathrm{e}-\mathrm{h})$ indicate clearly that the $\mathrm{S}$ and $\mathrm{O}$ elements are distributed discretely on the continuous $\mathrm{C}, \mathrm{N}$ elemental background.

The crystal structures of the pristine $\mathrm{g}-\mathrm{C}_{3} \mathrm{~N}_{4}$ nanosheets, the S-doped and the S-O codped $\mathrm{g}-\mathrm{C}_{3} \mathrm{~N}_{4}$ were demonstrated by their XRD patterns. As shown in Fig. 2(a), the XRD pattern for the pristine $\mathrm{g}-\mathrm{C}_{3} \mathrm{~N}_{4}$ displays two distinct diffraction peaks located at $2 \theta$ of about $13.1^{\circ}$ and $27.3^{\circ}$, which are in good accordance with the characteristic peaks of $\mathrm{g}-\mathrm{C}_{3} \mathrm{~N}_{4}$. These peaks correspond to the (100) and (002) crystal planes of g- $\mathrm{C}_{3} \mathrm{~N}_{4}$ attributed to the lattice planes parallel to the $c$-axis and the stacking of the conjugated aromatic systems in the layered structure, ${ }^{15,29,31,38}$ respectively. With $\mathrm{S}$ and $\mathrm{O}$ doped $\mathrm{g}-\mathrm{C}_{3} \mathrm{~N}_{4}$, the $2 \theta$ position for the lattice peak (002) increases a little bit to $27.5^{\circ}$ from the $27.3^{\circ}$ of the pure $\mathrm{g}-\mathrm{C}_{3} \mathrm{~N}_{4}$. This indicates that the interplanar stacking distance becomes smaller after $\mathrm{S}$ and $\mathrm{O}$ doping, since the dopant elements of $\mathrm{S}$ and $\mathrm{O}$ have changed the localized 

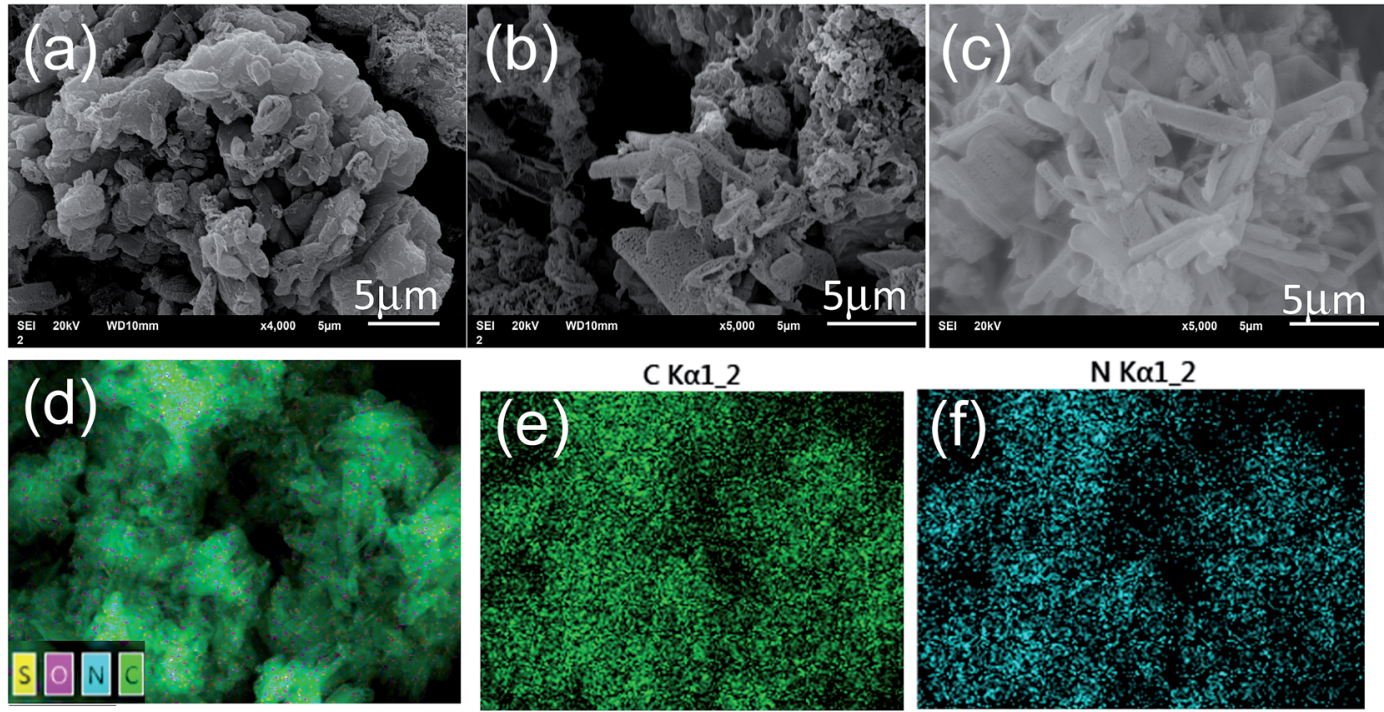

N Kal_2

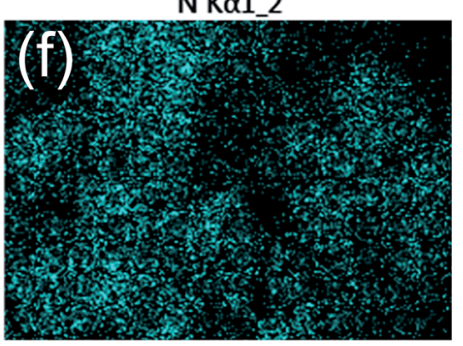

$\mathrm{S} \mathrm{K} \alpha 1$

$\mathrm{O} K \alpha 1$
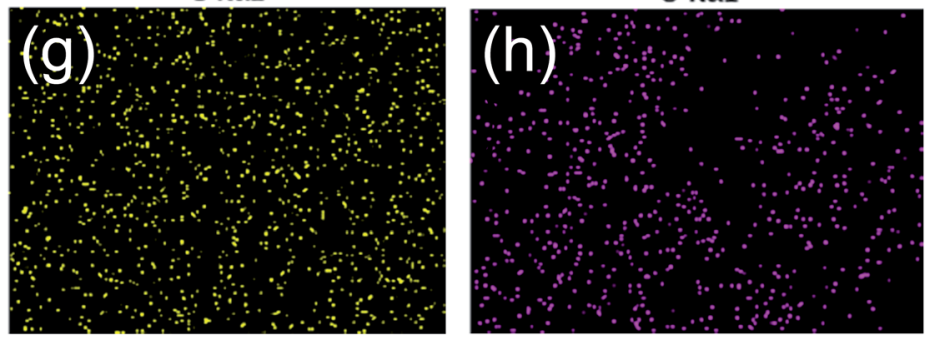

Fig. 1 The SEM images of (a) pristine g- $\mathrm{C}_{3} \mathrm{~N}_{4}$ nanosheets, (b) S doped and (c) S-O codoped g- $\mathrm{C}_{3} \mathrm{~N}_{4}$. Elemental EDS overlapped images of $\mathrm{C}$, N, S and $O(d)$ and mappings for $C(e), N(f), S(g)$ and $O(h)$.
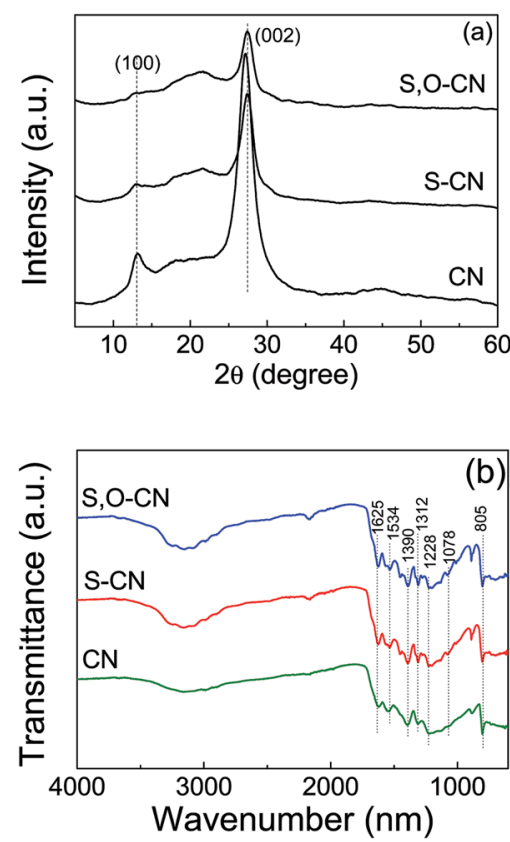

Fig. 2 XRD patterns (a) and FTIR spectra (b) of pristine $\mathrm{g}-\mathrm{C}_{3} \mathrm{~N}_{4}$ nanosheets $(\mathrm{CN})$, the $\mathrm{S}$ doped $(\mathrm{S}-\mathrm{CN})$ and $\mathrm{S}-\mathrm{O}$ codoped $\mathrm{g}-\mathrm{C}_{3} \mathrm{~N}_{4}$ $(\mathrm{S}, \mathrm{O}-\mathrm{CN})$ electronic structures compared to the substituted $\mathrm{N}$ atoms. The stronger attraction between the $\mathrm{g}-\mathrm{C}_{3} \mathrm{~N}_{4}$ layers would result in shorter interplanar distances. ${ }^{38}$ The XRD results indicate that the $\mathrm{S}$ and $\mathrm{O}$ atoms have been incorporated into the $\mathrm{g}-\mathrm{C}_{3} \mathrm{~N}_{4}$ layer.

The FTIR spectra of the pristine $\mathrm{g}-\mathrm{C}_{3} \mathrm{~N}_{4}$ nanosheets, the $\mathrm{S}$ doped and the $\mathrm{S}-\mathrm{O}$ codped $\mathrm{g}-\mathrm{C}_{3} \mathrm{~N}_{4}$ are depicted in Fig. 2(b), in which the typical characteristic peaks at 1228, 1312, 1390, 1534, and $1625 \mathrm{~cm}^{-1}$ can be assigned to the stretching modes of the aromatic $\mathrm{C}-\mathrm{N}$ heterocycle and the peak at $805 \mathrm{~cm}^{-1}$ is ascribed to the breathing mode of the triazine units. This demonstrates that the original graphitic $\mathrm{C}-\mathrm{N}$ network was kept intact. The peak at $1228 \mathrm{~cm}^{-1}$ corresponds to aromatic $\mathrm{C}-\mathrm{N}, \mathrm{C}-\mathrm{O}$ and might represent $\mathrm{S}-\mathrm{O}$ stretching vibrations. ${ }^{34}$ Compared to the pristine $\mathrm{g}-\mathrm{C}_{3} \mathrm{~N}_{4}$, a new peak at $1078 \mathrm{~cm}^{-1}$ appears in the FTIR spectra for the $\mathrm{O}$ doped and $\mathrm{S}-\mathrm{O}$ codoped $\mathrm{g}-\mathrm{C}_{3} \mathrm{~N}_{4}$, which can be attributed to the stretching mode of the $\mathrm{C}-\mathrm{O}$ or $\mathrm{C}-\mathrm{S}$ bond, which confirms that the oxygen and sulfur are doped into the $\mathrm{g}-\mathrm{C}_{3} \mathrm{~N}_{4}$ lattice. This is consistent with the FTIR results of the stretching vibration of $\mathrm{C}-\mathrm{O}$ reported by $\mathrm{Ma}$ et $a .^{26}$ and Seredych et al. ${ }^{34}$

XPS measurement was carried out to further investigate the chemical state and element valence changes of the pristine $\mathrm{g}$ $\mathrm{C}_{3} \mathrm{~N}_{4}$ and the $\mathrm{g}-\mathrm{C}_{3} \mathrm{~N}_{4}$ after $\mathrm{S}$ and $\mathrm{S}-\mathrm{O}$ doping. Fig. 3 shows the high-resolution XPS spectra of $\mathrm{C}, \mathrm{N}, \mathrm{O}$ and $\mathrm{S}$ elements of the pristine $\mathrm{g}-\mathrm{C}_{3} \mathrm{~N}_{4}$, and the S-doped, and $\mathrm{S}-\mathrm{O}$ codoped $\mathrm{g}-\mathrm{C}_{3} \mathrm{~N}_{4}$. The high-resolution $\mathrm{C}$ 1s XPS spectra of the three samples are shown in Fig. 3(a). For the pristine $\mathrm{g}-\mathrm{C}_{3} \mathrm{~N}_{4}$ nanosheets, the peak 

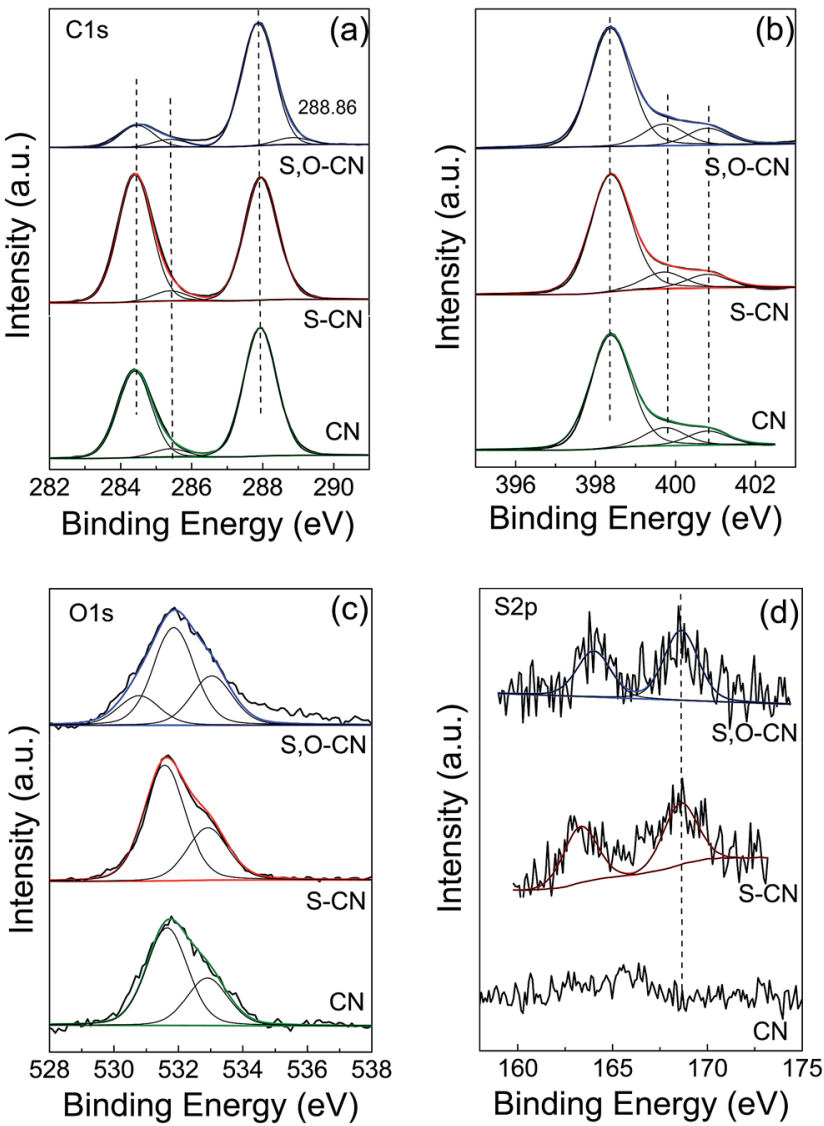

Fig. 3 XPS high resolution spectra for $C$ 1s (a) and $N$ is (b), O 1s (c) and $\mathrm{S} 2 \mathrm{p}$ (d) of the pristine $\mathrm{g}-\mathrm{C}_{3} \mathrm{~N}_{4}$ nanosheets ( $\mathrm{CN}$ ) and $\mathrm{S}$ doped $\mathrm{g}-\mathrm{C}_{3} \mathrm{~N}_{4}$ $(\mathrm{S}-\mathrm{CN})$ and $\mathrm{S}-\mathrm{O}$ codoped $\mathrm{g}-\mathrm{C}_{3} \mathrm{~N}_{4}(\mathrm{~S}, \mathrm{O}-\mathrm{CN})$.

centered at about $288.4 \mathrm{eV}(\mathrm{C} 1)$ is typically attributed to the $\mathrm{sp}^{2} \mathrm{C}$ atoms bonded to $\mathrm{N}$-containing aromatic skeleton rings $(\mathrm{N}-\mathrm{C}=\mathrm{N})$ coordination. The peak at $285.48 \mathrm{eV}(\mathrm{C} 2)$ is attributed to $\mathrm{C}-\mathrm{NH}_{2}$ bonded in the triazine ring of the reactant intermediary product. $^{21,23}$ The peak at $284.6 \mathrm{eV}$ (C3) could be attributed to adventitious carbon contamination $(\mathrm{C}-\mathrm{C}$ and $\mathrm{C}=\mathrm{C}){ }^{15,38}$ The $\mathrm{O}$ doped $\mathrm{g}-\mathrm{C}_{3} \mathrm{~N}_{4}$ shows a newly generated peak at $288.86 \mathrm{eV}$ ascribed to the $\mathrm{C}-\mathrm{O}=\mathrm{C}$ bond, which indicates that $\mathrm{O}$ atoms could be directly bonded to $\mathrm{sp}^{2}$-hybridized carbon in the $\mathrm{g}-\mathrm{C}_{3} \mathrm{~N}_{4}$ layer. The $\mathrm{N} 1 \mathrm{~s}$ spectra for pristine $\mathrm{g}-\mathrm{C}_{3} \mathrm{~N}_{4}$ in Fig. 3(b) can be mainly decomposed to three typical peaks located at about $398.4 \mathrm{eV}(\mathrm{N} 1), 399.7 \mathrm{eV}(\mathrm{N} 2)$, and $401.0 \mathrm{eV}$ (N3), which could be attributed to the $\mathrm{sp}^{2}$-hybridized aromatic $\mathrm{N}$ atoms bonded to carbon atoms $(\mathrm{C}-\mathrm{N}=\mathrm{C}), \mathrm{sp}^{3}$-hybridized $\mathrm{N}$ atoms of $\mathrm{N}(-\mathrm{C})_{3}$ and terminal amino functions $\left(\mathrm{C}-\mathrm{NH}_{2}\right)$, respectively. ${ }^{23,38} \mathrm{The} \mathrm{S}$ atomic dopant does not change the chemical shift of the $\mathrm{C} 1 \mathrm{~s}$ spectrum since the element $\mathrm{S}$ has similar electronegativity compared to the $\mathrm{C}$ atom. The $\mathrm{N}$ 1s spectra remain unchanged since $\mathrm{S}$ and $\mathrm{O}$ elements substitute the $\mathrm{N}$ atoms in the $\mathrm{g}_{-} \mathrm{C}_{3} \mathrm{~N}_{4}$ lattice.

In the $\mathrm{O} 1 \mathrm{~s}$ spectrum for the pristine $\mathrm{g}-\mathrm{C}_{3} \mathrm{~N}_{4}$ in Fig. 3(c), the peak at $532.88 \mathrm{eV}$ is ascribed to $-\mathrm{O}^{-}$in water or chemisorbed oxygen species. And the peak at $531.68 \mathrm{eV}$ could be ascribed to $\mathrm{O}=\mathrm{C}$ in carbonyl or $\mathrm{O}=\mathrm{S}$ in sulfoxide residual introduced in the preparation process. ${ }^{34}$ After $\mathrm{O}$ doping, a new peak at
$530.78 \mathrm{eV}$ appeared, which can be attributed to the formation of $\mathrm{C}-\mathrm{O}$ and $\mathrm{N}-\mathrm{C}-\mathrm{O}$ in the $\mathrm{g}-\mathrm{C}_{3} \mathrm{~N}_{4}$ lattice. There is also a new peak at a higher binding energy of $288.86 \mathrm{eV}$ in the $\mathrm{C} 1 \mathrm{~s}$ spectrum ascribed to the $\mathrm{C}-\mathrm{O}=\mathrm{C}$ bond. This result indicates that the $\mathrm{O}$ atom is bonded to the $\mathrm{sp}^{2}$-C by substituting the $\mathrm{N}$ atom. The peak at $531.68 \mathrm{eV}$ increases slightly compared to that of the pristine $\mathrm{g}-\mathrm{C}_{3} \mathrm{~N}_{4}$, since the intermediate sulfoxide products increase after reacting with TCA. As for the $\mathrm{S}$ and S-O doped $\mathrm{g}$ $\mathrm{C}_{3} \mathrm{~N}_{4}$, an $\mathrm{S} 2 \mathrm{p}$ peak located at $164.0 \mathrm{eV}$ can be reasonably assigned to $\mathrm{C}-\mathrm{S}$ bonds formed in the $\mathrm{g}_{-} \mathrm{C}_{3} \mathrm{~N}_{4}$ lattice via substituting $\mathrm{N}$. The peak at $168.6 \mathrm{eV}$ is ascribed to $\mathrm{S}=\mathrm{O}$ in the intermediate product of sulfoxide resulting from the decomposing TCA. ${ }^{34,38}$ By removing the adventitious carbon contamination, the $\mathrm{C} / \mathrm{N}$ atomic ratio is 0.74 for the pristine $\mathrm{g}-\mathrm{C}_{3} \mathrm{~N}_{4}$, which is fairly close to the stoichiometric value of $g-\mathrm{C}_{3} \mathrm{~N}_{4}$. The $\mathrm{C} /$ $\mathrm{N}$ atomic ratio for the $\mathrm{S}$, $\mathrm{O}$ codoped $\mathrm{g}-\mathrm{C}_{3} \mathrm{~N}_{4}$ is about 0.76 , which is slightly larger that that of the pristine $\mathrm{g}-\mathrm{C}_{3} \mathrm{~N}_{4}$. XPS results show that the $\mathrm{S}$ and $\mathrm{O}$ atoms have been doped into the $\mathrm{g}-\mathrm{C}_{3} \mathrm{~N}_{4}$ lattice and may preferentially substitute $\mathrm{N}$ atoms. For the $\mathrm{S}-\mathrm{O}$ codoped g- $\mathrm{C}_{3} \mathrm{~N}_{4}$, the $\mathrm{S}$ content is about $0.08 \%$ and the $\mathrm{O}$ content is about $0.15 \%$.

The photoabsorption property of the S-O codoped $\mathrm{g}-\mathrm{C}_{3} \mathrm{~N}_{4}$, as shown in Fig. 4(a), was investigated by measuring the UV-vis absorbance spectra in the range of 300 to $800 \mathrm{~nm}$. There is a sharp absorption edge for the pristine $\mathrm{g}-\mathrm{C}_{3} \mathrm{~N}_{4}$ nanosheets at around $460 \mathrm{~nm}$ indexing to a band gap energy of about $2.7 \mathrm{eV}$, which is firmly associated with the photocatalytic property in visible light. ${ }^{34,38}$ The Kubelka-Munk plots in Fig. 4(b) show that the adsorption edge is red shifted with lower bonding energy of $2.4 \mathrm{eV}$ for the S-doped $\mathrm{g}-\mathrm{C}_{3} \mathrm{~N}_{4}$ and $2.3 \mathrm{eV}$ for the S-O codped $\mathrm{g}$ $\mathrm{C}_{3} \mathrm{~N}_{4}$. The absorption intensity is remarkably enhanced in the visible region after the $\mathrm{S}$ and $\mathrm{O}$ doping. ${ }^{37}$ The absorption peaks around $300-400 \mathrm{~nm}$ are assigned to $\pi-\pi^{*}$ transitions in the conjugated ring systems, including heterocyclic aromatics. The features near $500 \mathrm{~nm}$ are due to $\mathrm{n}-\pi^{*}$ transitions involving lone pairs on the edge $\mathrm{N}$ atoms of the triazine rings and the intensity increases for the $\mathrm{S}$, $\mathrm{O}$ codoped $\mathrm{g}-\mathrm{C}_{3} \mathrm{~N}_{4}$ compared with the pristine $\mathrm{g}-\mathrm{C}_{3} \mathrm{~N}_{4}$. SEM images have shown that $\mathrm{S}$ and $\mathrm{O}$ doping causes the $\mathrm{g}-\mathrm{C}_{3} \mathrm{~N}_{4}$ sheets to curl up. The crimped structure facilitates the $\mathrm{n}-\pi^{*}$ transitions. These results reveal that the S-O doping g- $\mathrm{C}_{3} \mathrm{~N}_{4}$ composites could significantly promote the optical absorption performance and enhance the utilized efficiency of solar light, which subsequently results in its promotion of the photocatalytic activity. ${ }^{37}$

Photoluminescence (PL) spectra were carried out to investigate the recombination/separation of photoinduced charge carriers in the pristine $\mathrm{g}-\mathrm{C}_{3} \mathrm{~N}_{4}$ nanosheets and the S-O codoped $\mathrm{g}^{-} \mathrm{C}_{3} \mathrm{~N}_{4}$ under the excitation wavelength of $273 \mathrm{~nm}$. The measured PL spectra, shown in Fig. 4(c), showed that all of the samples exhibit a main emission peak appearing at about $440 \mathrm{~nm}$, which is consistent with the reported value in the literature ${ }^{36,37}$ Compared to the pristine g- $\mathrm{C}_{3} \mathrm{~N}_{4}$, the S-O doped $\mathrm{g}-\mathrm{C}_{3} \mathrm{~N}_{4}$ shows weaker PL intensity, revealing the lower recombination probability of photoinduced electrons and holes, ${ }^{37}$ which could give rise to a higher photocatalytic activity.

Electrochemical impedance spectra (EIS) of the pristine g$\mathrm{C}_{3} \mathrm{~N}_{4}$ and the $\mathrm{g}-\mathrm{C}_{3} \mathrm{~N}_{4}$ doped with $\mathrm{O}$ and $\mathrm{S}$ were measured to 

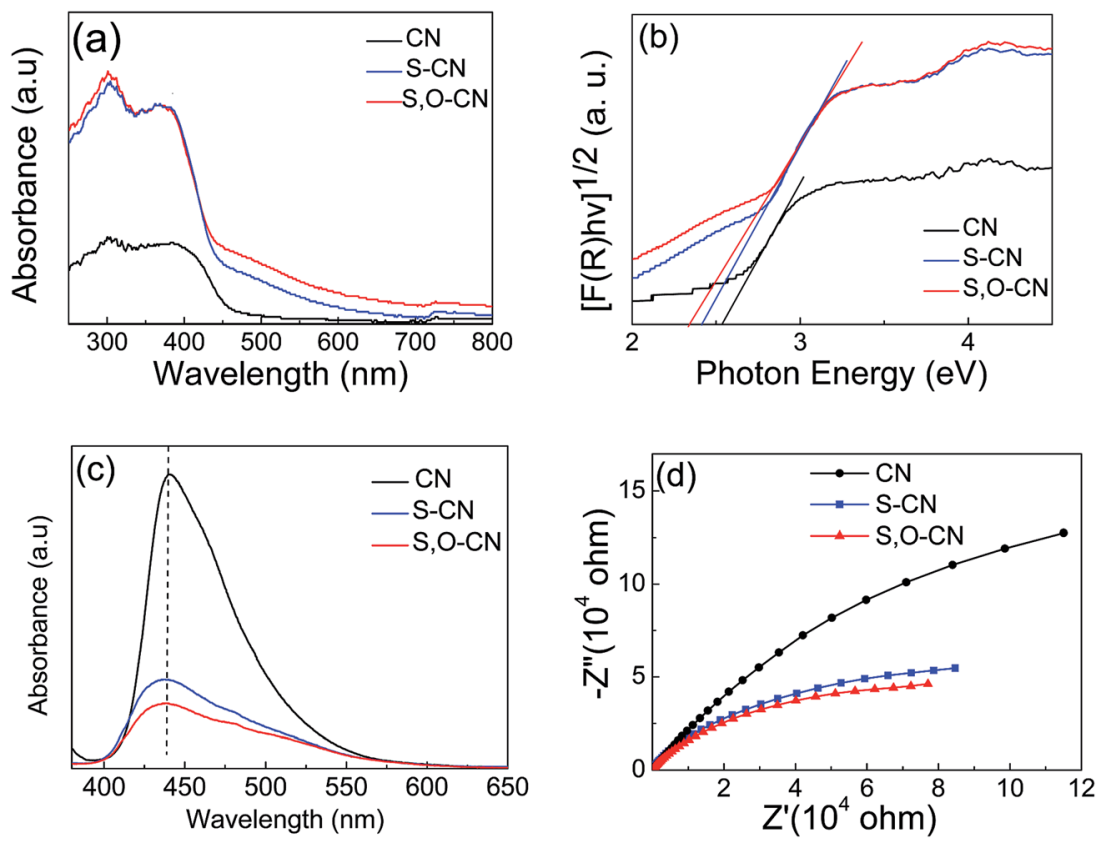

Fig. 4 (a) UV-vis absorbance spectra, (b) corresponding Kubelka-Munk plots, (c) PL and (d) EIS spectra of the pure g- $\mathrm{C}_{3} \mathrm{~N}_{4}$ nanosheets and $\mathrm{S}$ doped $\mathrm{g}-\mathrm{C}_{3} \mathrm{~N}_{4}$ and $\mathrm{S}-\mathrm{O}$ codoped $\mathrm{g}-\mathrm{C}_{3} \mathrm{~N}_{4}$.

understand the photocatalytic mechanism. The arc on the EIS Nyquist plot indicates the charge transfer resistance. Generally speaking, the smaller the arc radius, the lower the charge transfer resistance will be. ${ }^{15,37}$ As shown in Fig. 4(d), the Nyquist plots of all the $\mathrm{O}$ and $\mathrm{S}$ doped $\mathrm{g}-\mathrm{C}_{3} \mathrm{~N}_{4}$ samples demonstrate a smaller arc radius attributed to the reduced electronic resistance and increased electronic conductivity by doping with $\mathrm{O}$ and $\mathrm{S}$ elements compared to the pristine $\mathrm{g}-\mathrm{C}_{3} \mathrm{~N}_{4}$. Similarly, the arc radius for $\mathrm{S}-\mathrm{O}$ codoped $\mathrm{g}-\mathrm{C}_{3} \mathrm{~N}_{4}$ is smallest in all three samples, which is associated with the highest efficiency of the charge separation. ${ }^{36}$ Moreover, it is vital that the change trend of the arc radius for $\mathrm{g}-\mathrm{C}_{3} \mathrm{~N}_{4}$ samples is roughly consistent with the results displayed in the PL spectra.

The photocatalytic performance of S-O doped $\mathrm{g}-\mathrm{C}_{3} \mathrm{~N}_{4}$ was evaluated by $\mathrm{RhB}$ degradation under visible light irradiation (Fig. 5(a)). After $3 \mathrm{~h}$ of irradiation with visible light, about $48 \%$ of the RhB is degraded in presence of the $\mathrm{S}$ doped $\mathrm{g}-\mathrm{C}_{3} \mathrm{~N}_{4}$, compared to only $20 \%$ of the RhB being decomposed in the presence of the pristine $\mathrm{g}-\mathrm{C}_{3} \mathrm{~N}_{4}$. As for the S-O codoped g- $\mathrm{C}_{3} \mathrm{~N}_{4}$, approximately $75 \%$ of RhB is decomposed after $3 \mathrm{~h}$ of visible light irradiation. Fig. 5(b) shows the first-order reaction kinetics for the RhB degradation, which is expressed as $-\ln \left(C / C_{0}\right)=k t$, where $k$ is the reaction rate, and $t$ is the reaction time. The photocatalytic performance of the S-O doped ${ }^{-}-\mathrm{C}_{3} \mathrm{~N}_{4}$ is 6 times that of the pristine $\mathrm{g}-\mathrm{C}_{3} \mathrm{~N}_{4}$ calculated from the results in Fig. 5(b). The stability of the S-O codoped g- $\mathrm{C}_{3} \mathrm{~N}_{4}$ was evaluated by recycle experiments for RhB degradation. After $3 \mathrm{~h}$ of visible light irradiation, the catalysts were retrieved by centrifugation and a subsequent drying process and used for the next RhB degradation test. The photocatalytic performance was investigated in fresh material and after three recycles, as shown in Fig. 5(c). No obvious difference was observed after three recycles, indicating that the $\mathrm{S}-\mathrm{O}$ codoped $\mathrm{g}-\mathrm{C}_{3} \mathrm{~N}_{4}$ is relatively stable under visible light irradiation.

A theoretical investigation was carried out to further understand the effect of different atomic doping on the electrical structure of the $\mathrm{g}-\mathrm{C}_{3} \mathrm{~N}_{4}$ layer. We performed density functional theory (DFT) calculations using the Gaussian09 software package for the $\mathrm{O}$ and $\mathrm{S}$ doped monolayer $\mathrm{g}_{-} \mathrm{C}_{3} \mathrm{~N}_{4}$. DFT B3LYP/6$31 \mathrm{G}(\mathrm{d})$ level of theory was used to optimize the geometry of g$\mathrm{C}_{3} \mathrm{~N}_{4}$ and to calculate the natural orbital population distribution. The calculation of HOMO and LUMO, and density of state were based on the DFT B3PW91/6-31G(d) level.

Fig. 6 shows the highest occupied molecular orbital (HOMO) and the lowest unoccupied molecular orbital (LUMO) for the (001) lattice plane of the $\mathrm{g}_{-}-\mathrm{C}_{3} \mathrm{~N}_{4}$ monolayer. The calculated HOMO for the pristine $g-\mathrm{C}_{3} \mathrm{~N}_{4}$ suggests that the edge $\mathrm{N}$ atoms provide the sites for oxidation of water to $\mathrm{O}_{2}$, whereas the LUMO indicates that the $\mathrm{C}$ and the inner $\mathrm{N}$ atoms are the preferred reduction sites to form $\mathrm{H}_{2}{ }^{40}$ The migration of the photogenerated $\mathrm{e}^{-} / \mathrm{h}^{+}$pairs is not efficient due to the differently localized HOMO and LUMO. No HOMO and LUMO present on the bridge $\mathrm{N}$ atoms inhibits the carrier migration from one heptazine unit to another and this reduces the photocatalytic performance. The substitution of the edge $\mathrm{N}$ with $\mathrm{O}$ causes slightly more strongly delocalized HOMO and LUMO compared to the pristine g- $\mathrm{C}_{3} \mathrm{~N}_{4}$ monolayer. The dispersion of the HOMO and LUMO distribution can enhance the carrier mobility. The substitution of the edge $\mathrm{N}$ with $\mathrm{S}$ causes more strongly delocalized HOMO and LUMO, and thus increases the number of reactive sites. ${ }^{36,40}$ It is noted that the bridge $\mathrm{N}$ can act as a channel to connect the adjacent heptazine unit and facilitate the migration of photogenerated electron/hole pairs. The geometry for the $\mathrm{S}$ doped $\mathrm{g}^{-} \mathrm{C}_{3} \mathrm{~N}_{4}$ monolayer is inclined to 

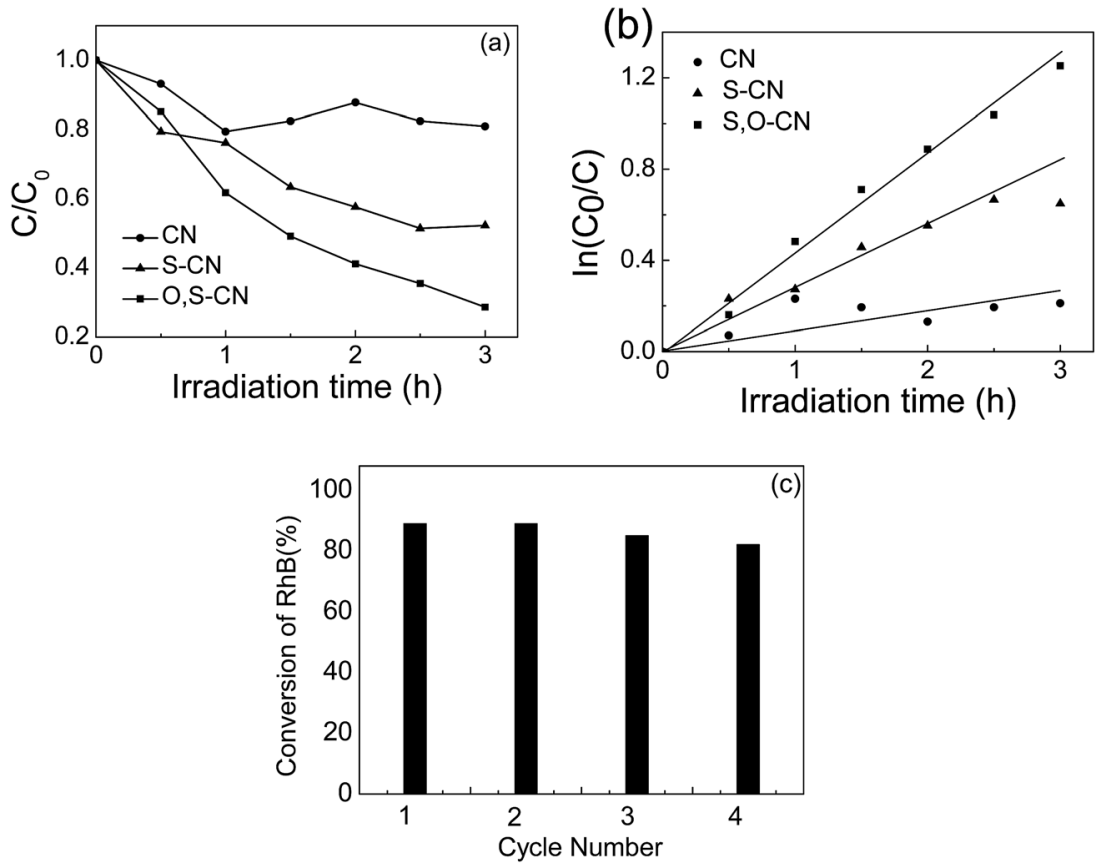

Fig. 5 (a) Photocatalytic performances and (b) corresponding first-order reaction kinetics in the degradation of RhB under visible light irradiation for the pristine $\mathrm{g}-\mathrm{C}_{3} \mathrm{~N}_{4}$, the $\mathrm{S}$ doped and $\mathrm{S}-\mathrm{O}$ codoped g- $\mathrm{C}_{3} \mathrm{~N}_{4}$. (c) Stability test of the $\mathrm{S}-\mathrm{O}$ codoped g- $\mathrm{C}_{3} \mathrm{~N}_{4}$.

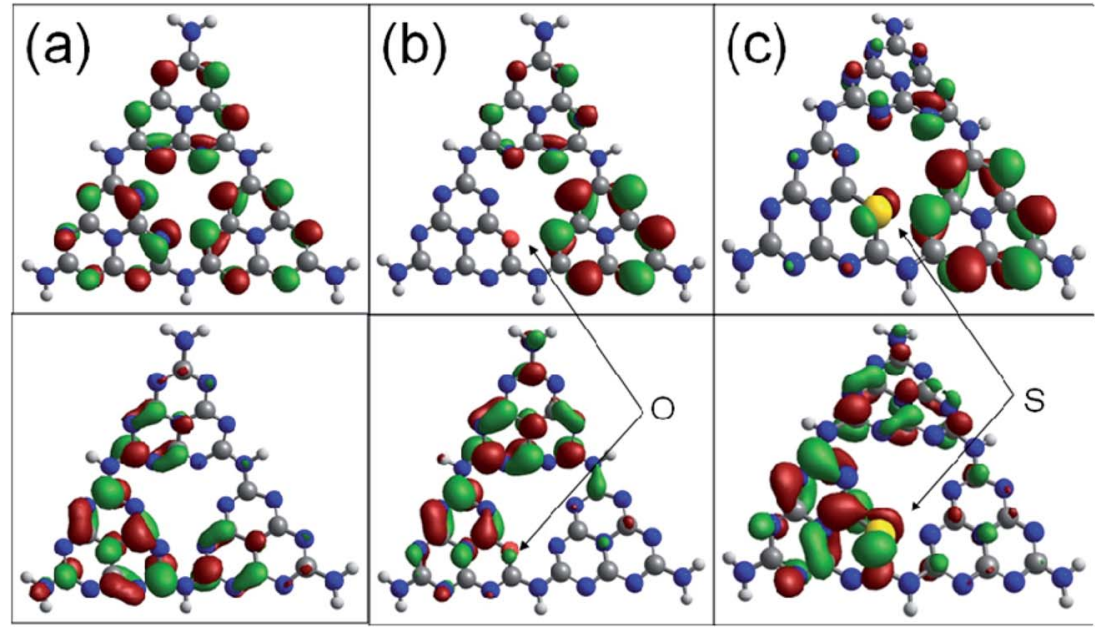

Fig. 6 Calculated HOMO (top) and LUMO (bottom) of the pristine (a), $\mathrm{O}$ doped (b) and $\mathrm{S}$ doped (c) $\mathrm{g}-\mathrm{C}_{3} \mathrm{~N}_{4}$ monolayer. The isosurface is taken at a value of $0.003 e / \mathrm{Bohr}^{3}$. Carbon atoms are in grey and nitrogen in blue.

deform and become crimped, which is consistent with the morphology shown in the SEM image.

The total and partial density of state (DOS) for the pristine $\mathrm{g}$ $\mathrm{C}_{3} \mathrm{~N}_{4}$ are shown in Fig. 7(a). The DOS in the valance bond is mainly contributed by the carbon and nitrogen atoms, while the DOS in the conductance bond is from the nitrogen atoms. The band gap narrows upon the $\mathrm{S}$ and $\mathrm{O}$ doping and the Fermi level is shifted to the conducting band, as shown in Fig. 7(b) and (c). The intensity and wave profile of the partial DOS for $\mathrm{C}$ and $\mathrm{N}$ are similar in the ranges of -20 to $-12 \mathrm{eV}$ and $-5 \mathrm{eV}$ to the Fermi level for the $\mathrm{g}-\mathrm{C}_{3} \mathrm{~N}_{4}$ monolayer, which indicates that the orbitals of $\mathrm{C}$ and $\mathrm{N}$ hybridized. The $\mathrm{S}$ dopant contributes more DOS compared with the $\mathrm{O}$ dopant and the partial DOS of S elements near the Fermi level is stronger that that of $\mathrm{O}$ elements. ${ }^{\mathbf{3 6 4 0}}$

The calculated natural orbital population distribution showed that the valence electron configuration of the carbon atom is $2 \mathrm{~s}^{0.74-0.76} 2 \mathrm{p}^{2.60-2.61}$. The valence electron of the carbon atoms alters imperceptibly after the $\mathrm{O}$ and $\mathrm{S}$ doping, and the modification disappears far away from the dopant atoms. The valence electron configurations of the doped $\mathrm{O}$ and $\mathrm{S}$ are $2 \mathrm{~s}^{1.59} 2 \mathrm{p}^{4.89}, 3 \mathrm{~s}^{1.67} 3 \mathrm{p}^{3.95}$, respectively. The electron orbitals of the doped $\mathrm{O}$ and $\mathrm{S}$ have hybridized with those of other atoms, covalently binding with adjacent atoms. The valence electron divergence between the dopant atoms and the adjacent intrinsic 

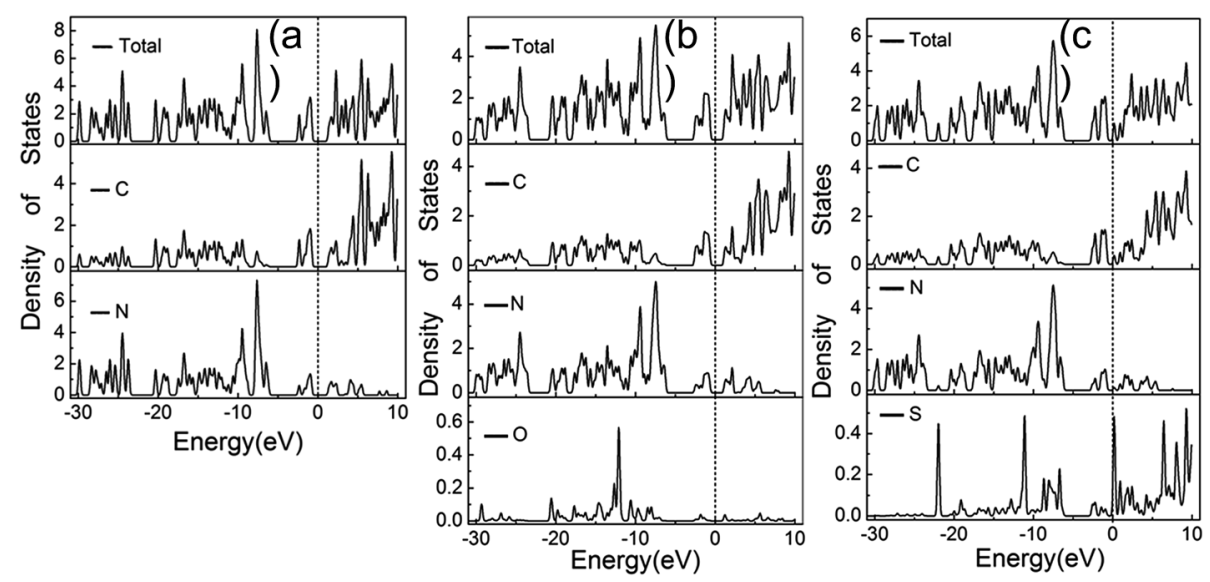

Fig. 7 Calculated total and partial DOS plots of C, N, O and S elements for the pristine (a), O doped (b) and (c) S doped g- $\mathrm{C}_{3} \mathrm{~N}_{4}$ monolayer.

atoms yields a new energy band in the $\mathrm{g}_{-} \mathrm{C}_{3} \mathrm{~N}_{4}$ monolayer, thus changing its photocatalytic performance.

Finally, a clearer picture can be drawn by taking abovementioned experimental and theoretical strands into consideration. The semiconductor photocatalysis process involves the generation, the separation and transfer, and the recombination of photoinduced charge carriers under visible light excitation. Non-metal element doping causes slightly delocalized HOMO and LUMO, and tunes the semiconductor band structure and the band gap as well. XPS and XRD results showed that the $\mathrm{O}$ and $\mathrm{S}$ atoms substitute the $\mathrm{N}$ atoms in the $\mathrm{g}_{-} \mathrm{C}_{3} \mathrm{~N}_{4}$ lattice by forming $\mathrm{O}-\mathrm{C}$ and $\mathrm{S}-\mathrm{C}$ bonds and leaving the $\mathrm{N}$ 1s spectra unchanged after $\mathrm{O}$ and $\mathrm{S}$ doping. The $\mathrm{O}$ and $\mathrm{S}$ doping has narrowed the band gap by the UV-vis spectra, and promotes the optical absorption performance. In addition, the PL and EIS spectra confirm the higher separation and transfer efficiency of the photoinduced charge carriers. The DFT calculations show that dispersion of the HOMO and LUMO distribution can enhance the carrier mobility. For the pristine $\mathrm{g}-\mathrm{C}_{3} \mathrm{~N}_{4}$, no HOMO and LUMO are present on the bridge $\mathrm{N}$ atoms, thus suppressing the carrier migration from one heptazine unit to another and reducing the photocatalytic performance. The substitution of the edge $\mathrm{N}$ with $\mathrm{S}$ causes more strongly delocalized HOMO and LUMO, thus increasing the number of reactive sites. ${ }^{33,36}$ It is noted that the bridge $\mathrm{N}$ can act as a channel to connect the adjacent heptazine unit and facilitate the migration of photogenerated electron/hole pairs by increasing the density of state around the bridge $\mathrm{N}$ atoms. The $\mathrm{g}-\mathrm{C}_{3} \mathrm{~N}_{4}$ layers doped with $\mathrm{S}$ and $\mathrm{O}$ result in an integrated effect under visible light irradiation, having largely promoted the separation and suppressed the recombination of photoexcited charge carriers, thus achieving a higher photocatalytic activity than that of the pristine g- $\mathrm{C}_{3} \mathrm{~N}_{4}$.

\section{Conclusion}

In summary, the doped $\mathrm{S}$ and $\mathrm{O}$ atoms substituting the lattice $\mathrm{N}$ atoms facilitate the separation and transfer of the photoinduced electron-hole pairs. The crimped structure resulting from the $\mathrm{S}$ and $\mathrm{O}$ doping enhanced UV-vis absorption by boosting the $\mathrm{n}-\pi^{*}$ transition. The photocatalytic performance for $\mathrm{RhB}$ degradation increases 6 fold compared to the pristine g- $\mathrm{C}_{3} \mathrm{~N}_{4}$ nanosheets. The more strongly delocalized HOMO and LUMO and narrower band gap by $\mathrm{S}$ and $\mathrm{O}$ doping facilitate the photoexcitation and migration of photoinduce charge carriers, thus enhancing the photocatalytic performance.

\section{Author contributions}

The manuscript was written through contributions of all authors. All authors have given approval to the final version of the manuscript.

\section{Acknowledgements}

This work was financially supported by the National Natural Science Foundation of China (Grant No. 21173170).

\section{References}

1 X. Wang, K. Maeda, A. Thomas, K. Takanabe, G. Xin, J. M. Carlsson, K. Domen and M. Antonietti, A metal-free polymeric photocatalyst for hydrogen production from water under visible light, Nat. Mater., 2009, 8, 76-80.

2 W. J. Ong, L. L. Tan, Y. H. Ng, S. T. Yong and S. P. Chai, Graphitic carbon nitride $\left(\mathrm{g}-\mathrm{C}_{3} \mathrm{~N}_{4}\right)$-based photocatalysts for artificial photosynthesis and environmental remediation: are we a step closer to achieving sustainability?, Chem. Rev., 2016, 116, 7159-7329.

3 A. B. Jorge, D. J. Martin, M. T. S. Dhanoa, A. S. Rahman, N. Makwana, J. Tang, A. Sella, F. Cora, S. Firth, J. A. Darr and P. F. McMillan, $\mathrm{H}_{2}$ and $\mathrm{O}_{2}$ evolution from water halfsplitting reactions by graphitic carbon nitride materials, $J$. Phys. Chem. C, 2013, 117, 7178-7185.

$4 \mathrm{H}$. Yan, Soft-templating synthesis of mesoporous graphitic carbon nitride with enhanced photocatalytic $\mathrm{H}_{2}$ evolution under visible light, Chem. Commun., 2012, 48, 3430-3432.

5 J. Zhang, F. Guo and X. Wang, An optimized and general synthetic strategy for fabrication of polymeric carbon 
nitride nanoarchitectures, Adv. Funct. Mater., 2013, 23, 30083014.

6 P. Li, W. Zhang, Y. Zhang, Y. Sun and F. Dong, $\left(\mathrm{NH}_{4}\right)_{2} \mathrm{SO}_{4^{-}}$ assisted polycondensation of dicyandiamide for porous $\mathrm{g}$ $\mathrm{C}_{3} \mathrm{~N}_{4}$ with enhanced photocatalytic NO removal, RSC Adv., 2016, 6, 96334-96338.

7 Y. Tian, B. Chang, J. Lu, J. Fu, F. Xi and X. Dong, Hydrothermal synthesis of graphitic carbon nitride- $\mathrm{Bi}_{2} \mathrm{WO}_{6}$ heterojunctions with enhanced visible light photocatalytic activities, ACS Appl. Mater. Interfaces, 2013, 5, 7079-7085.

8 L. Ye, D. Wang and S. Chen, Fabrication and enhanced photoelectrochemical performance of $\mathrm{MoS}_{2} / \mathrm{S}$-doped g- $\mathrm{C}_{3} \mathrm{~N}_{4}$ heterojunction film, ACS Appl. Mater. Interfaces, 2016, 8, 5280-5289.

9 M. Xu, L. Han and S. Dong, Facile fabrication of highly efficient $\mathrm{g}-\mathrm{C}_{3} \mathrm{~N}_{4} / \mathrm{Ag}_{2} \mathrm{O}$ heterostructured photocatalysts with enhanced visible-light photocatalytic activity, ACS Appl. Mater. Interfaces, 2013, 5, 12533-12540.

10 S. Kumar, T. Surendar, A. Baruah and V. Shanker, Synthesis of a novel and stable $\mathrm{g}-\mathrm{C}_{3} \mathrm{~N}_{4}-\mathrm{Ag}_{3} \mathrm{PO}_{4}$ hybrid nanocomposite photocatalyst and study of the photocatalytic activity under visible light irradiation, J. Mater. Chem. A, 2013, 1, 53335340.

11 S. Kumar, A. Baruah, S. Tonda, B. Kumar, V. Shanker and B. Sreedhar, Cost-effective and eco-friendly synthesis of novel and stable $\mathrm{N}$-doped $\mathrm{ZnO} / \mathrm{g}-\mathrm{C}_{3} \mathrm{~N}_{4}$ core-shell nanoplates with excellent visible-light responsive photocatalysis, Nanoscale, 2014, 6, 4830-4842.

12 J. Liu, S. Xie, Z. Geng, K. Huang, L. Fan, W. Zhou, L. Qiu, D. Gao, L. Ji, L. Duan, L. Lu, W. Li, S. Bai, Z. Liu, W. Chen, S. Feng and Y. Zhang, Carbon nitride supramolecular hybrid material enabled high-efficiency photocatalytic water treatments, Nano Lett., 2016, 16, 6568-6575.

13 J. Zhang, G. Zhang, X. Chen, S. Lin, L. Möhlmann, G. Dołega, G. Lipner, M. Antonietti, S. Blechert and X. Wang, Comonomer control of carbon nitride semiconductors to optimize hydrogen evolution with visible light, Angew. Chem., Int. Ed., 2012, 124, 3237-3241.

14 K. Tian, W.-J. Liu and H. Jiang, Comparative investigation on photoreactivity and mechanism of biogenic and chemosythetic $\mathrm{Ag} / \mathrm{C}_{3} \mathrm{~N}_{4}$ composites under visible light irradiation, ACS Sustainable Chem. Eng., 2015, 3, 269-276.

15 L. Chen, Y. H. Man, Z. Q. Chen and Y. P. Zhang, $A g / g-C_{3} N_{4}$ layered composites with enhanced visible light photocatalytic performance, Mater. Res. Express, 2016, 3, 115003.

16 L. Ge, C. Han, J. Liu and Y. Li, Enhanced visible light photocatalytic activity of novel polymeric g- $\mathrm{C}_{3} \mathrm{~N}_{4}$ loaded with Ag nanoparticles, Appl. Catal., A, 2011, 409, 215-222.

17 J. Yu, K. Wang, W. Xiao and B. Cheng, Photocatalytic reduction of $\mathrm{CO}_{2}$ into hydrocarbon solar fuels over $\mathrm{g}-\mathrm{C}_{3} \mathrm{~N}_{4}-$ Pt nanocomposite photocatalysts, Phys. Chem. Chem. Phys., 2014, 16, 11492-11501.

18 Z. Ni, F. Dong, H. Huang and Y. Zhang, New insights into how Pd nanoparticles influenced the photocatalytic oxidation and reduction ability of $\mathrm{g}^{-} \mathrm{C}_{3} \mathrm{~N}_{4}$ nanosheets, Catal. Sci. Technol., 2016, 6, 6448-6458.
19 G. Jiang, X. Li, M. Lan, T. Shen, X. Lv, F. Dong and S. Zhang, Monodisperse bismuth nanoparticles decorated graphitic carbon nitride: Enhanced visible-light-response photocatalytic NO removal and reaction pathway, Appl. Catal., B, 2017, 205, 532-540.

20 G. Dong, K. Zhao and L. Zhang, Carbon self-doping induced high electronic conductivity and photoreactivity of $\mathrm{g}-\mathrm{C}_{3} \mathrm{~N}_{4}$, Chem. Commun., 2012, 48, 6178-6180.

21 J. Fang, H. Fan, M. Li and C. Long, Nitrogen self-doped graphitic carbon nitride as efficient visible light photocatalyst for hydrogen evolution, J. Mater. Chem. A, 2015, 3, 13819-13826.

22 S. C. Yan, Z. S. Li and Z. G. Zou, Photodegradation of rhodamine $\mathrm{B}$ and methyl orange over boron-doped g- $\mathrm{C}_{3} \mathrm{~N}_{4}$ under visible light irradiation, Langmuir, 2010, 26, 38943901.

23 D. Gao, Y. Liu, P. Liu, M. Si and D. Xue, Atomically thin B doped $\quad \mathrm{g}-\mathrm{C}_{3} \mathrm{~N}_{4} \quad$ nanosheets: high-temperature ferromagnetism and calculated half-metallicity, Sci. Rep., 2016, 6, 35768.

24 N. Sagara, S. Kamimura, T. Tsubota and T. Ohno, Photoelectrochemical $\mathrm{CO}_{2}$ reduction by a p-type borondoped $\mathrm{g}-\mathrm{C}_{3} \mathrm{~N}_{4}$ electrode under visible light, Appl. Catal., B, 2016, 192, 193-198.

25 Y. Zhang, T. Mori, J. Ye and M. Antonietti, Phosphorusdoped carbon nitride solid: enhanced electrical conductivity and photocurrent generation, J. Am. Chem. Soc., 2010, 132, 6294-6295.

26 T. Y. Ma, J. Ran, S. Dai, M. Jaroniec and S. Z. Qiao, Phosphorus-doped graphitic carbon nitrides grown in situ on carbon-fiber paper: flexible and reversible oxygen electrodes, Angew. Chem., Int. Ed., 2015, 54, 4646-4650.

27 S. Hu, L. Ma, J. You, F. Li, Z. Fan, F. Wang, D. Liu and J. Gui, A simple and efficient method to prepare a phosphorus modified g- $\mathrm{C}_{3} \mathrm{~N}_{4}$ visible light photocatalyst, RSC Adv., 2014, 4, 21657-21663.

28 Y. Zhou, L. Zhang, J. Liu, X. Fan, B. Wang, M. Wang, W. Ren, J. Wang, M. Li and J. Shi, Brand new P-doped g$\mathrm{C}_{3} \mathrm{~N}_{4}$ enhanced photocatalytic activity for $\mathrm{H}_{2}$ evolution and rhodamine $\mathrm{B}$ degradation under visible light, J. Mater. Chem. A, 2015, 3, 3862-3867.

29 J. Hong, X. Xia, Y. Wang and R. Xu, Mesoporous carbon nitride with in situ sulfur doping for enhanced photocatalytic hydrogen evolution from water under visible light, J. Mater. Chem., 2012, 22, 15006.

$30 \mathrm{~L}$. Ye and S. Chen, Fabrication and high visible-light-driven photocurrent response of $\mathrm{g}-\mathrm{C}_{3} \mathrm{~N}_{4}$ films: the role of thiourea, Appl. Surf. Sci., 2016, 389, 1076-1083.

31 G. Liu, P. Niu, C. Sun, S. C. Smith, Z. Chen, G. Q. Lu and $\mathrm{H}$. Cheng, Unique electronic structure induced high photoreactivity of sulfur-doped graphitic $\mathrm{C}_{3} \mathrm{~N}_{4}, J . A m$. Chem. Soc., 2010, 132, 11642-11648.

32 L. Cao, R. Wang and D. Wang, Synthesis and characterization of sulfur self-doped $\mathrm{g}-\mathrm{C}_{3} \mathrm{~N}_{4}$ with efficient visible-light photocatalytic activity, Mater. Lett., 2015, 149, 50-53. 
33 J. Chen, Z. Hong, Y. Chen, B. Lin and B. Gao, One-step synthesis of sulfur-doped and nitrogen-deficient g- $\mathrm{C}_{3} \mathrm{~N}_{4}$ photocatalyst for enhanced hydrogen evolution under visible light, Mater. Lett., 2015, 145, 129-132.

34 M. Seredych and T. J. Bandosz, Nitrogen enrichment of Sdoped nanoporous carbon by $\mathrm{g}_{-}-\mathrm{C}_{3} \mathrm{~N}_{4}$ : insight into photosensitivity enhancement, Carbon, 2016, 107, 895-906.

35 J. Hong, X. Xia, Y. Wang and R. Xu, Mesoporous carbon nitride with in situ sulfur doping for enhanced photocatalytic hydrogen evolution from water under visible light, J. Mater. Chem., 2012, 22, 1500615012.

36 S. Stolbov and S. Zuluaga, Sulfur doping effects on the electronic and geometric structures of graphitic carbon nitride photocatalyst: insight from first principles, J. Phys.: Condens. Matter, 2013, 25, 085507.

37 Z. F. Huang, J. Song, L. Pan, Z. Wang, X. Q. Zhang, J. Zou, W. Mi, X. W. Zhang and L. Wang, Carbon nitride with simultaneous porous network and O-doping for efficient solar-energy-driven hydrogen evolution, Nano Energy, 2015, 12, 646-656.

38 J. Li, B. Shen, Z. Hong, B. Lin, B. Gao and Y. Chen, A facile approach to synthesize novel oxygen-doped $\mathrm{g}-\mathrm{C}_{3} \mathrm{~N}_{4}$ with superior visible-light photoreactivity, Chem. Commun., 2012, 48, 12017-12019.

39 H. Ma, Y. Li, S. Li and N. Liu, Novel P-O codoped g- $\mathrm{C}_{3} \mathrm{~N}_{4}$ with large specific surface area: hydrothermal synthesis assisted dissolution-precipitation process and their visible light activity under anoxic conditions, Appl. Surf. Sci., 2015, 357, 131-138.

40 J. Cui, S. Liang, X. Wang and J. Zhang, First principle modeling of oxygen-doped monolayer graphitic carbon nitride, Mater. Chem. Phys., 2015, 161, 194-200. 